\title{
POLÍTICAS PÚBLICAS CULTURAIS E SUSTENTÁVEIS: O CASE DO PRÉDIO DO INSTITUTO SÃO PAULO APÓSTOLO - ISPA, EM FRUTAL/MG
}

\author{
(iD) http://orcid.org/0000-0001-6124-4111 Sócrates José de Queiroz dos Santos ${ }^{11}$ \\ Whitps://orcid.org/0000-0002-9193-4604 Prof. Dr. Marcelo Pessoa ${ }^{12}$ \\ DOI NUMBER: 10.33726/akedia2447-7656v4a32017p50-77
}

\begin{abstract}
RESUMO: Este artigo realiza um breve estudo acerca do reconhecimento da valoração imaterial e incorpórea arraigadas no espírito da comunidade de Frutal/MG. Tendo em vista que a compreensão desse patrimônio imaterial congrega valores culturais e sociais, objetivos e subjetivos, de preservação e de sustentabilidade, empreendemos uma pesquisa bibliográfica, buscando compreender o status quo da questão em Frutal - MG. Desse modo, nosso objetivo, é encontrar o mecanismo de valoração social e cultural do imóvel hoje denominado ISPA - Instituto São Paulo Apóstolo, bem como delimitar o território de responsabilidade do poder público sobre a memória e a história cultural da cidade e dos cidadãos no que se refere ao patrimônio cultural em foco.
\end{abstract}

PALAVRAS-CHAVE: Poder Público, Patrimônio Cultural e Imaterial, Valor Histórico e Cultural, Bem Inventariado, Desenvolvimento Sustentável.

ABSTRACT: This article performs a brief study about recognition of intangible and incorporeal valuation rooted in the spirit of the community of Frutal/MG. Considering that the understanding of this intangible heritage brings together cultural and social values, objective and subjective, of preservation and sustainability, we undertook a literature search, seeking to understand the status quo of the matter Frutal - MG. In this way, we aim to find the mechanism of social and cultural valuation of the property today named ISPA - Instituto São Paulo Apóstolo, as well as define the territory of responsibility of public authorities on memory and the cultural history of the city and citizens with regard to cultural heritage in focus.

KEYWORDS: Government, Cultural Heritage and Intangible Heritage, Historical And Cultural Value as Well Inventoried, Sustainable Development.

\footnotetext{
${ }^{11}$ Mestrando em Filosofia, Sociologia e Antropologia pela FATEC - Faculdade de Tecnologia de Votuporanga/SP. Pós-Graduado em Gestão Pública pela FaPP. Graduado em Direito pela Universidade do Estado de Minas Gerais UEMG. Pós-Graduado em Direito do Trabalho e Direito Processual Civil, pela FIJRJ - Faculdades Integradas de Jacarepaguá do Rio de Janeiro.

${ }^{12}$ Orientador do Programa de Pós-Graduação da FaPP. Docente na UEMG, Unidade Frutal. Possui Bolsa de Professor Orientador - BPO. Desenvolve Projeto de Pesquisa com o apoio da UEMG e do Estado de Minas Gerais, via prêmio de fomento à pesquisa docente obtido por meio do Edital PAPq 08/2015.
} 


\title{
ISSN 2447-7656 - Volume IV - Ano III - 2017 \\ Edição Especial
}

\section{INTRODUÇÃO}

Como sabido, a cultura se expressa pela exteriorização dos "modos de criar, fazer e viver" (Constituição Federal de 1988, art. 216). Assim, aqueles trejeitos de um determinado povo, a forma de sua comunicação, as danças, as histórias, as formas com que constroem suas residências ou uma determinada edificação que, conforme a importância para o seu povo, pode envolver toda uma comunidade, também se incluem no que chamamos de Cultura.

É um mecanismo expressivo pelo qual se traspassam as gerações, à medida que cria ou recria novas ações, valores e sentidos, formando o patrimônio cultural de um povo.

A noção de cultura, posta assim, deixa de se relacionar exclusivamente com a cultura erudita e passa a englobar manifestações populares de cultura e também de cultura de massa. Na lapidar lição de Leonardo Castriota ${ }^{13}$, passase a considerar a questão imaterial da formação do significado - a dimensão viva da cultura. Essa valoração imaterial, incorpórea e arraigada no espírito comunitário local também exige a devida proteção e preservação. São valores intrínsecos e extrínsecos do imóvel do ISPA (Instituto São Paulo Apóstolo), os quais se vinculam à memória e à história cultural da cidade e dos cidadãos ${ }^{14}$ :

\begin{abstract}
Valor Histórico: a história da construção está relacionada com a história da cidade de Frutal, tendo em vista que se configura como o primeiro ginásio e primeira escola normal desta localidade. Especificamente sobre este valor cabe dizer ainda que o imóvel se constituiu há mais de 60 (sessenta) anos, como testemunha viva da luta dos cidadãos frutalenses - em comunidade - pela educação local. $O$ imóvel foi o resultado da iniciativa popular, exaltada e contada por diversas fontes bibliográficas que se ocupam da narração histórica do Município de Frutal para as presentes e futuras gerações.
\end{abstract}

Valor Evocativo: Constata-se que o imóvel permeia o imaginário dos cidadãos frutalenses, máxime quando se revelou que o local foi amplamente utilizado para fins sociais (espaço de convivência e aprendizado).

13 CASTRIOTA, Leonardo Barci. Patrimônio Cultural: conceitos, politicas, instrumentos. São Paulo: Annablume. Belo Horizonte: IEDS, 2009, p. 11-15.

${ }^{14}$ Cf. Ação Civil Pública proposta pelo Ministério Público Estadual sob o n.0 0271.13.0092569 em trâmite perante a $1^{\mathrm{a}}$ Vara Cível de Frutal/MG. 
Valor Paisagístico: Este valor se destaca quando se analisa a relevância da implantação do imóvel no contexto urbano. Corresponde a ampliação do conceito de patrimônio arquitetônico que se considera o entorno e a ambiência. O imóvel foi edificado em área ampla. A quadra tem dimensões maiores que as demais, ocupando uma área correspondente a aproximadamente 03 (três) quadras do Bairro Alto Boa Vista. Possui volumetria predominante e localização privilegiada, daí o seu valor ambiental, paisagístico e de referência, devido à forte presença na paisagem urbana. A manutenção do imóvel, portanto, condiz com a preservação do equilíbrio da paisagem.

Valor afetivo: Constitui referencial simbólico para o espaço e memória da cidade, despertando sentimentos de identidade e pertencimento.

Valor de acessibilidade com vistas à revitalização/reciclagem: Facilidade de conexão da edificação com o sistema viário e a capacidade de integração com os equipamentos de lazer e cultura da cidade.

Valor de compatibilização com a estrutura urbana: A presença do prédio não impede as reformulações urbanas com a construção de novos empreendimentos no terreno.

Valor arquitetônico: Apesar das intervenções ao longo das décadas de existência da edificação, predomina o estilo de construção que remete ao art decó e protomoderno, estilos comuns aos colégios construídos na mesma época (anos 50 - Século XX).

Daí, a importância de se cuidar e preservar desses apontamentos representativos da história e da cultura de uma sociedade, a fim de se manter viva a sua identidade. E vejamos que se trata não só disso, mas de zelar pela duração e conservação de obras de artes, monumentos, objetos, edifícios, os usos e costumes, com o objetivo de perpetuar o valor intrínseco de indivíduos e das sociedades como valor coadjuvante da cidadania e da qualidade de vida.

Ocorre, no entanto, que nem sempre esta iniciativa é vista com bons olhos aos interesses de alguém, de um grupo ou da sociedade como um todo. Razão pela qual, pode-se imaginar como poder legítimo instituído, justamente pelo zelo do bem da comunidade, os Poderes Executivo e Legislativo como atores principais no processo de guarda da memória, o que, conforme demonstrado no presente trabalho, não postulam verdades absolutas, podendo

\section{ISSN 2447-7656 - Volume IV - Ano III - 2017 Edição Especial, Dezembro}


ser também provocado o Poder Judiciário e o Ministério Público Estadual, curador do Patrimônio Histórico e Cultural de uma localidade.

Importante ressaltar que um determinado bem, para se constituir em patrimônio cultural, deve ser fruto de uma elaboração narrativa, simbólica, política, que acontece mediada por um conjunto de saberes técnicos na dotação de valor, tendo em vista a responsabilidade de guarda deste bem, o que implica sempre em seleção, ou seja, significa dizer que diante de um universo imenso de bens culturais, foram eleitos alguns e não outros para serem patrimônios.

Neste contexto, Frutal/MG se configura num bom exemplo deste tipo de sítio patrimonial, uma vez que tem registros que remontam ao ano de 1835. Assim, temos um pré-requisito histórico, a partir do qual se podem valorar os bens que tenham densidade histórica, sob pena de que nenhum subsista ao passar do tempo com suas características estruturais e valores referenciais, em especial a edificação denominada Instituto São Paulo Apóstolo - ISPA, cujo valor histórico e cultural já fora reconhecido ao ser declarado como bem inventariado.

Assim, havendo o bem a ser salvaguardado pelo Poder Público, há que se exigir que este seja protegido dentro de políticas públicas de desenvolvimento sustentável na promoção da qualidade de vida e do bemestar social de seus habitantes, sob pena de não perdurar no tempo.

Desse modo, por meio de uma ampla revisão bibliográfica, no primeiro trecho de nosso texto, apresentamos alguns aspectos históricos relacionados ao Instituto São Paulo Apóstolo - ISPA, que são importantes a serem considerados acadêmica e juridicamente falando.

$\mathrm{Na}$ segunda seção, reportamo-nos aos elementos materiais, sociais e culturais que contribuem para a instituição da valoração do patrimônio histórico. 


\section{ISSN 2447-7656 - Volume IV - Ano III - 2017 Edição Especial, Dezembro}

Em seguida, discorremos sobre os dispositivos legais de proteção dos

valores históricos e culturais, seus conceitos, abrangências e as responsabilidades que cabem ao poder público.

Finalizando, damos, a saber, nossas conclusões e o cerne de nosso aporte bibliográfico.

\section{ASPECTOS HITÓRICOS}

A edificação, objeto de estudo no presente trabalho, foi construída no ano de 1952 , tendo por escopo o funcionamento da primeira entidade de ensino ${ }^{15}$ da cidade, denominada como "Ginásio Frutal". De acordo com informações extraídas da obra historiográfica Desbravadores do Carmo do Fructal - História e Genealogia de um Descendente, da lavra de Álvaro Ferreira de Paula ${ }^{16}$, a constituição do "Ginásio Frutal" se realizou em função de um grupo de estudantes que estavam passando férias de final de ano nesta cidade.

\footnotetext{
${ }^{15}$ Um ginásio é um tipo de escola de ensino secundário existente em alguns países. Por analogia,

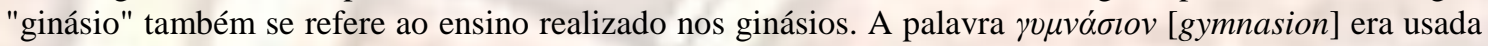
na Grécia antiga para designar o local destinado à educação física e à educação intelectual dos rapazes. Com o último significado, de educação intelectual, o termo continuou a ser bastante usado em algumas línguas - como o alemão - enquanto em outras línguas - como o português - o termo "ginásio" passou a ser empregado, sobretudo, com o sentido de educação física. Nos países germânicos, tradicionalmente, o ginásio constitui uma escola secundária vocacionada para a preparação dos alunos para acederem a uma universidade, com características muito semelhantes às dos tradicionais liceus da Europa latina. Os ginásios têm origem na Reforma Protestante, ocorrida no século XVI. O primeiro sistema de escolas a ministrar um ensino ginasial surgiu na Saxônia em 1528. Segundo o sistema educativo do tipo germânico, os ginásios destinam-se aos alunos com maior vocação acadêmica. Estes alunos são filtrados à saída do ensino primário, por volta dos 10 a 13 anos, só aos melhores sendo permitido aceder ao ginásio. Tradicionalmente, o ginásio foca-se nas humanidades e nos estudos clássicos, com o seu currículo a incluir normalmente o ensino do latim e do grego antigo. Outras modalidades do ensino ginasial incluem as línguas modernas, as ciências, a economia e as tecnologias Alguns outros países - a maioria deles na Europa de Leste - introduziram o ginásio nos seus sistemas educativos, mas com características diferentes dos ginásios germânicos. Estes ginásios não correspondem a um ramo do ensino secundário, mas sim a um nível de ensino. Normalmente, o ginásio constitui a primeira etapa do ensino secundário (equivalente aproximadamente aos segundos ciclos do ensino fundamental do Brasil e do ensino básico de Portugal), com o liceu a constituir a segunda etapa. Em alguns países, existe também o pró-ginásio que constitui o ciclo preparatório do ensino ginasial. Até 1971, no Brasil, o ginásio constituía o estágio educacional que se seguia ao ensino primário e que antecedia o ensino colegial. Correspondia aos quatro anos finais do atual ensino fundamental. Para aceder ao ensino ginasial, era necessária a realização de um exame de admissão, depois de finalizado o ensino primário. O ginásio tinha uma duração de quatro anos, findos os quais, o aluno poderia aceder ao colégio, que constituía o terceiro ciclo de estudos. Em 1971, o ginásio foi fundido com o ensino primário, dando origem ao ensino de $1^{\circ}$ grau. Na sequência da Lei de Diretrizes e Bases da Educação de 1996, o ensino de $1^{\circ}$ grau foi substituído pelo ensino fundamental. Disponível em: <http://pt.wikipedia.org/wiki/Gin\%C3\%A1sio_(escola)>. Acesso em 09/03/2015.

${ }^{16}$ PAULA, Álvaro Ferreira de. Desbravador do Carmo de Fructal - História e Genealogia de um Descendente. [s.1]: Edição Independente de 2004.
} 


\section{ISSN 2447-7656 - Volume IV - Ano III - 2017 Edição Especial, Dezembro}

Liderados por Joel Furtado (acadêmico do Curso de Direito), os estudantes promoveram a "Semana de Estudos" que agitou a sociedade frutalense, especialmente os cidadãos de posse e providos de poderes políticos.

O evento visava à constituição de uma "Sociedade Anônima" capaz de obter recursos necessários à instalação do Ginásio, ante o espírito de universalização do ensino que proliferava em território nacional, em meados do Século XX. Como resultado da iniciativa dos incansáveis cidadãos, marcou-se uma solenidade pública, ocasião em que os estudantes e interessados apresentaram um Plano de Ação que possibilitava a criação de uma entidade de ensino. Previa-se a participação do Poder Público Municipal (Prefeitura) e de mais 20 (vinte) cidadãos. Após acaloradas discussões, fez-se a leitura do anteprojeto estatutário de criação da sociedade. No dia 06 de abril de 1952, estava instituída a "Sociedade Anônima", cujas obras se iniciaram no mês de agosto de 1952. As atividades escolares, contudo, tiveram início no ano de 1955.

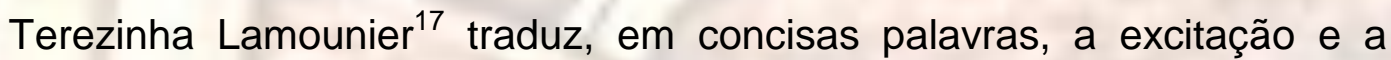
importância sociocultural e política daquele período embrionário da educação frutalense: "a instalação de um ginásio, em Frutal, era um sonho e uma necessidade premente. $\mathrm{O}$ início foi promissor. A escola foi altamente procurada e bem equipada para fazer do sonho uma legítima realidade". O imóvel guarda a memória da luta dos frutalenses por uma educação de qualidade, do engajamento dos estudantes locais na busca por seus direitos. O local, sem dúvida, é símbolo do anseio popular por formação e conhecimento, representando marco importante de um dos estágios de desenvolvimento e de civilização dos frutalenses. O Ginásio Frutal foi instituição responsável pelas formaturas de várias $4^{a}$ séries na cidade, demonstrando o impacto sociocultural positivo quando do início das atividades de ensino, conforme se infere da obra Original História de Frutal ${ }^{18}$.

${ }^{17}$ FERREIRA, Terezinha Lamounier. Respingos de História III - Registro de Fatos Pessoais e Acontecimentos Históricos de Frutal. Frutal: Oficina das Artes Yara Lins, 2009, p. 7-58.

${ }^{18}$ FERREIRA, Jeová. Original História de Frutal. Frutal: Oficina de Artes Yara Lins, 2002, p. 105. 
Por motivos desconhecidos, o Ginásio Frutal e a entidade mantenedora entraram em crise financeira e, no ano de 1962, as "Irmãs Salvatorianas" assumiram a gestão do prédio e das respectivas atividades educacionais, ocasião em que assumiu o título de "Colégio Normal São José", cuja estrutura funcionou até meados do ano de 1971. Contudo, sem maiores esclarecimentos, as Irmãs Salvatorianas desistiram do empreendimento, embora tenham conquistado ilibada reputação e prestígio regional. Ao longo dos anos, sucederam a gestão anterior, o ISPA (Instituto São Paulo Apóstolo), a "APAE" (Associação dos Pais e Amigos dos Excepcionais) e o "Colégio Objetivo", o qual manteve atividades no prédio até o ano de 2007.

A FAF (Faculdade Frutal), embora tenha alugado a edificação, não chegou a instalar as atividades de ensino superior no local. Enquanto mantido sob a gestão do ISPA (Instituto São Paulo Apóstolo), o prédio foi utilizado para a realização de festas, reuniões, encontros de jovens, concílios, ultréias, quermesses, aulas de catequese etc. De averbar, ainda, que no imóvel também funcionou uma creche da Prefeitura Municipal, em meados dos anos 80 (já no Século XX). Atualmente, o prédio, cuja propriedade é da Arquidiocese de Uberaba - Paróquia Nossa Senhora do Carmo, está sem a devida utilização, desde o ano de 2007. Passando pelo local, sobreleva notar que a estrutura do bem e alguns elementos originais estão em bom estado de conservação. Contudo, o abandono do imóvel e sua falta de uso estão ocasionando grave deterioração, não sendo pretensioso dizer que há risco de incêndio. Porquanto, moradores de rua, andarilhos e usuários de drogas têm o mau vezo de utilizar o local como abrigo, onde utilizam substâncias entorpecentes, fumam cigarros, consomem álcool de maneira indiscriminada e amontoam lixo de toda sorte. Quem não poderia prever que, numa situação assim, degradada, não se possam atear fogo em restos de mobiliários, papeis, jornais, etc., causando incontrolável incêndio e consequentes perdas irreversíveis ao patrimônio histórico e cultural?

\section{ISSN 2447-7656 - Volume IV - Ano III - 2017 Edição Especial, Dezembro}


Nota-se pela vegetação rasteira e arbustiva, em avançado estágio de regeneração, no entorno do edifício histórico, que se deflagra risco da ocorrência de incêndios ou da propagação de insetos e vetores, inclusive em relação aos moradores vizinhos, pois não há zelo ou cuidado com a limpeza e a higienização urbana (interna ou externa) do imóvel.

Embora a Administração Pública Municipal de Frutal tenha instaurado procedimento administrativo destinado ao tombamento do bem imóvel, com fundamento no artigo 12 e consectários da Lei Ordinária n. ${ }^{\circ}$ 4.867/2001, o bem não foi tombado, encontrando-se somente inventariado para tal.

Diante destes fatos, iniciou-se, por parte da Administração Pública Municipal, um movimento para a construção de um edifício de moradias de alto padrão, fato que, aos olhos da administração, eliminaria a problemática do abandono do local ao tempo que se daria a devida utilização ao terreno de localidade privilegiada.

Ocorre, no entanto, que outro movimento se formou, a fim de pleitear justamente o contrário: sua conservação e devida utilização pelo poder público.

Formado justamente por aquelas pessoas que conheciam a história do Instituto São Paulo Apóstolo - ISPA, algumas por terem frequentado suas dependências como alunos, outros como professores e até mesmo pessoas que participaram da construção do prédio, o Ministério Público Estadual foi acionado, o qual passou a colher informações e ouvir pessoas interessadas no desfecho. Durante a instrução do procedimento administrativo instaurado na Curadoria do Patrimônio Histórico e Cultural, apurou-se que o bem estava dotado de condições imensuráveis de historicidade e sua manutenção era vital para manter viva a memória e a luta da sociedade frutalense quanto ao início de sua escolarização.

\section{ISSN 2447-7656 - Volume IV - Ano III - 2017 Edição Especial, Dezembro}


Por outro lado, também se apurou que a Gestão Pública atual não estava disposta a arcar com o custeio de manutenção do referido imóvel, nem buscar uma solução viável e amigável, dando por certo que iria pleitear judicialmente sua demolição para a construção do plano residencial arquitetado com empresas já interessadas, pois, para ela, o simples fato de o bem estar inventariado não era óbice jurídico.

Também se pode observar que, apesar de haver uma Secretaria de Cultura, a mesma, por meio de seu secretário, defendia a posição adotada pelo Executivo Municipal, deixando claro desconhecer os valores do imóvel, bem como a legislação patrimonial em nível nacional e local.

Assim, não restou alternativa, a não ser o intento, por parte do Ministério Público, de uma ação em busca de uma decisão judicial para que não somente se impedisse a demolição do referido imóvel, como também se obrigasse a Gestão Pública Municipal a gerir o custeio da restauração do imóvel, juntamente com a Arquidiocese de Uberaba, ação qual se encontra em trâmite, apesar de uma decisão em primeiro grau favorável.

\section{VALORAÇÃO DO PATRIMÔNIO IMATERIAL}

A edificação em pauta constitui um dos últimos bastiões de relevância histórica e cultural do Município de Frutal e região. O antigo prédio, hoje combalido pela inutilização, é um exemplo de manifestação e perpetuação da história e da cultura local. Durante várias décadas funcionou com fins educacionais e cumpriu - com êxito - esta missão constitucional.

Grande parte dos cidadãos frutalenses estudou nas dependências em apreço e se tornaram homens e mulheres bem sucedidos, cônscios de seus deveres cívicos. Os frutos do trabalho desenvolvido naquela edificação permanecerão na memória dos que participaram de sua existência. 
Vê-se, assim, que a materialidade e a imaterialidade do bem imóvel em tela estão intrinsecamente relacionadas.

Inadmissível que tão valioso patrimônio histórico, representante da memória de homens e mulheres ilustres da região, verdadeiros fundadores da cidade, pessoas que realmente contribuíram para a noção de progresso, pertencimento e de solidariedade humana, criando um horizonte de objetivos e fins comunitários, estimulando as gerações futuras a perseguirem incondicionalmente o bem comum, seja depredado e apagado da memória de um povo.

A descrição em tela demonstra a essência do valor cultural do antigo prédio e sua vinculação com a identidade e a memória do povo frutalense. Essa memória não pode ser apagada, extinta ou se evaporar respaldada por quaisquer meios que sejam. Indubitável que a edificação em exame é um dos exemplos do salto de desenvolvimento socioeconômico e humano da comunidade local, já no início da emancipação da cidade, transformando o Município de Frutal em um polo político e econômico da região do Pontal do Triângulo Mineiro. O prédio histórico, hoje, está exposto ao risco de ser destruído e transformado em ruínas, embaraçando-se nos obstáculos da burocracia, do tempo e do espaço, fomentando o desapego da comunidade aos valores do passado e aos objetivos do futuro.

\section{DO CONCEITO JURÍDICO-CONSTITUCIONAL DE PATRIMONNIO CULTURAL E DOS MECANISMOS DE PROTEC̃̃̃ DOS VALORES HISTÓRICOS E CULTURAIS NO ÂMBITO DAS POLÍTICAS PÚBLICAS DE DESENVOLVIMENTO SUSTENTÁVEL}

Preconiza o artigo 216, caput, da Magna Carta, de 1988, que constituem o patrimônio cultural brasileiro os bens de natureza material e imaterial que, tomados individualmente ou em conjunto, são portadores de referência à identidade, à ação, à memória dos diferentes grupos formadores da sociedade

\section{ISSN 2447-7656 - Volume IV - Ano III - 2017 Edição Especial, Dezembro}




\section{ISSN 2447-7656 - Volume IV - Ano III - 2017 Edição Especial, Dezembro}

brasileira, incluindo-se as formas de expressão; os modos de criar, fazer e viver; as criações científicas, artísticas e tecnológicas; as obras, objetos, documentos, edificações e demais espaços destinados às manifestações artístico culturais; os conjuntos urbanos e sítios de valor histórico, paisagístico, artístico, arqueológico, paleontológico, ecológico e científico.

Doravante, o mesmo dispositivo determinou que o Poder Público, com a colaboração da comunidade, promoverá e protegerá o patrimônio cultural brasileiro, por meio de inventários, registros, vigilância, tombamento e desapropriação, e de outras formas de acautelamento e preservação. No mesmo compasso, tem-se, na Constituição do Estado de Minas Gerais, que:

Art. 209 - O Estado, com a colaboração da comunidade, protegerá o patrimônio cultural por meio de inventários, registros, vigilância, tombamento e desapropriação, de outras formas de acautelamento e preservação e, ainda, de repressão aos danos e às ameaças a esse patrimônio.

Porém, se as pessoas forem indagadas nas ruas do Município de Frutal e região sobre o significado de patrimônio cultural, quase todos os entrevistados imaginarão que essa expressão encerra apenas as obras de arte e as manifestações eruditas da nação ou do mundo, tratando-se de bens corpóreos (casas, palácios, castelos, casarões, esculturas, etc.) de tempos muito remotos, de locais distantes e de séculos inimagináveis e já sepultados pela vida moderna. No entanto, o conceito de cultura ${ }^{19}$, do modo como aqui o adotamos, transcende essa visão restritiva, anacrônica e museográfica. Isto, porque a cultura é a maneira com a qual o homem se relaciona com a natureza e com os outros homens, ou seja, a maneira que um determinado grupo tem de cultivar a terra, as suas ferramentas, as manifestações arquitetônicas, suas construções, suas festas, seu modo de viver, interagir e fazer são partes de

\footnotetext{
${ }^{19}$ CASTRIOTA, Leonardo Barci. Patrimônio Cultural, Valores e Sociedade Civil. Artigo disponível em Mestres e Conselheiros. Manual de Atuação dos Agentes do Patrimônio Cultural. Belo Horizonte: IEDS, 2009 , p. 42.
} 
sua cultura e são tão importantes quanto à admiração das belas artes ou dos casarões da época colonial.

Logo, o conceito constitucional de patrimônio cultural cristaliza em suas manifestações as especialidades de uma cultura, por isso, o patrimônio cultural é o maior depositário da identidade de um povo e dos elementos diferenciais que o caracterizam. O bem cultural (material ou imaterial) tem a função social de orientar as populações e o cidadão no tempo e no espaço, colocando cada um como partícipe de um grupo comunitário que compartilha de uma história comum e de um lugar próprio no mundo, conferindo-Ihes a sensação de pertencimento sociocultural.

Muito mais que cimento, madeira, aço e formas arquitetônicas visíveis de um tempo já esquecido, os bens culturais exprimem valores de cidadania que foram agregados e cultivados pelas gerações que constituíram, de maneira dinâmica, a comunidade. Assim, em homenagem aos princípios do respeito à preexistência, da dignidade da pessoa humana e da solidariedade intergeracional, é dever da Administração Pública e da sociedade promover, preservar e proteger os bens que integram o patrimônio cultural, para as presentes e futuras gerações. Parafraseando Flávio de Lemos Carsalade, mesmo que portadores de uma mensagem do passado, os bens históricos somente possuem sentido se usufruídos no presente. Vejamos as lições do citado autor:

São os bens históricos que, também, nos orientam quando percorremos nossas cidades, através dos marcos arquitetônicos, por exemplo, ou que nos referenciam quando fruímos a nossa cultura ou quando compartilhamos nossa memória comum. Faz parte ainda dessa função social a consolidação de uma identidade coletiva, a qual faz reconhecernos como elos de uma comunidade e que estimula nossos laços afetivos e de cidadania. Portanto, para que o bem patrimonial possa exercer sua função mais ampla, tem que ser acessível e, para tanto, deve estar recuperado em sua potência (CARSALADE, 2009, p. 78).

\section{ISSN 2447-7656 - Volume IV - Ano III - 2017 Edição Especial, Dezembro}




\section{ISSN 2447-7656 - Volume IV - Ano III - 2017 Edição Especial, Dezembro}

Como bem assinalado pela síntese de Ana Maria Marchesan, na proteção do patrimônio cultural, deve-se tê-lo "como uma espécie de alicerce sobre o qual a civilização como um todo se edifica e evolui" (MARCHESAN, 2007. p. 49).

Salienta a mesma autora, que, "com apoio na ideia de que o ser humano necessita preservar seus laços e identidades pretéritas e presentes para edificar o futuro [..], não há que se falar em qualidade de vida". Assim, hodiernamente, múltiplos são os mecanismos constitucionais e infraconstitucionais de preservação e de proteção do patrimônio cultural. Logo, não é apenas o tombamento, enquanto espécie de servidão administrativa que serve a tal finalidade.

Neste trabalho, a edificação conhecida na comunidade frutalense como ISPA (Instituto São Paulo Apóstolo) encontra-se inventariada pela Administração Pública Municipal ${ }^{20}$. Consoante literatura léxica, inventariar significa descrever minuciosamente um bem. O inventário, ipsis literis, consiste no levantamento e identificação das características e valores particulares de um bem cultural, mediante à concorrência de métodos e técnicas apropriados.

Estas características são, dentre outras, de natureza morfológica, histórica, estética, artística, arquitetônica, social, paisagística, urbanística, antropológica, natural, além do estado de conservação e de dados que permitam localizar o bem cultural como autoria, data de construção ou criação, endereço completo e proprietário.

Para os bens móveis, cabe ainda fotografar de forma detalhada e para bens imóveis, além das fotos, o levantamento das plantas dos diversos níveis e fachadas e a indicação da situação do imóvel na cidade ou no meio rural, e da sua relação com o seu entorno. Uma das funções mais relevantes do inventário de um bem cultural é consolidar o interesse público, submetendo-o ao regime jurídico específico dos bens culturais protegidos conferindo-Ihes restrições.

\footnotetext{
${ }^{20} \mathrm{Cf}$ Disponível em: http://www.frutal.mg.gov.br/Cultura-Esporte-e-Lazer/bens-inventariados-
} imoveis.html Acesso: 20/03/2015. 
Inventariar, para a teleologia do texto Constitucional, com fincas no Direito Comparado (cujos fundamentos vêm de Portugal, Espanha e França), implica na dualidade e complementaridade: conhecer para, em seguida, proteger. Em outras palavras, sendo o inventário uma das formas constitucionais de preservação, gera-se o dever de manutenção do estado do bem na sua condição inicial, assim como desperta o dever de promover a função social, econômica e ambiental da propriedade.

A somarem-se a isso, os proprietários de bens inventariados devem facilitar o acesso dos órgãos competentes e conservá-los devidamente, consultando sempre os órgãos responsáveis pelo inventário na hipótese de intervenções, alienações ou modificações de qualquer natureza. Vale dizer: o inventário constitui instrumento jurídico-administrativo autônomo com efeitos concretos imediatos que não se vinculam ao procedimento administrativo do tombamento. Pode-se afirmar que o inventário tem natureza de ato administrativo declaratório restritivo, visto que implica no reconhecimento, por parte do poder público, da importância cultural de determinado bem, derivando, a partir da consolidação do ato, outros efeitos jurídicos voltados ao interesse supraindividual de preservação. Nesse diapasão, forçoso reconhecer que o poder constituinte originário extirpou da ordem jurídica a obtusa noção de que haveria a necessidade do prévio tombamento para a preservação de bens culturais. Ocorre que a questão independe do tombamento e sequer pressupõe procedimento administrativo dessa natureza, tendo-se em mente que o edifício já se encontra inventariado.

O inventário, neste sentido, é o procedimento administrativo pelo qual o poder público identifica e cadastram os bens culturais do Município, com o objetivo de subsidiar as ações administrativas e legais de preservação, tendo por finalidade:

\section{ISSN 2447-7656 - Volume IV - Ano III - 2017 Edição Especial, Dezembro}


I - promover, subsidiar e orientar ações de políticas públicas de preservação e valorização do patrimônio cultural; II - mobilizar e apoiar a sociedade civil na salvaguarda do patrimônio cultural; III - promover o acesso ao conhecimento e à fruição do patrimônio cultural; IV - subsidiar ações de educação ambiental nas comunidades e nas redes de ensino pública e privada.

Em linhas gerais, observa-se que o inventário é considerado como sendo um cadastro de bens de valor sociocultural, caracterizando-se, sem sombra de dúvida, como forma autônoma e autoaplicável de preservação do meio ambiente cultural, ao qual pode ser conferido status de instrumento declaratório da importância de determinado bem.

A seu turno, a professora Sônia Rabello de Castro, em sua obra O Estado na Preservação de Bens Culturais, dedicou o texto da introdução para asseverar sobre a importância do tema, proporcionando a seguinte lição:

Comumente costuma-se entender e usar como se sinônimos fossem os conceitos de preservação e de tombamento. Porém é importante distingui-los, já que diferem quanto a seus efeitos no mundo jurídico, mormente para a apreensão mais rigorosa do que seja o ato de tombamento. Preservação é o conceito genérico. Nele podemos compreender toda e qualquer ação do Estado que vise a conservar a memória de fatos ou valores culturais de uma Nação. É importante acentuar este aspecto já que, do ponto de vista normativo, existem várias possibilidades de formas legais de preservação. A par da Legislação, há também as atividades administrativas do Estado que, sem restringir ou conformar direitos, caracterizam-se como ações de fomento ou têm como consequência a preservação da memória. Portanto, o conceito de preservação é genérico, não se restringindo a uma única lei, ou forma e preservação específica (CASTRO, 1991, p. 05).

Como anteriormente sublinhado, figura o tombamento como uma das múltiplas formas de acautelamento de um bem que possui valor cultural ou histórico reconhecido pelo Poder Público e pela sociedade. 
Entretanto, a preservação não possui uma única faceta deste prisma, traduzindo-se num conjunto de ações que podem ser tomadas pelo Poder Público ou mesmo por particulares que visem à manutenção da memória de uma população com referência a fatos e dados históricos.

Com efeito, o legislador constituinte federal e estadual dispensou tratamento especial à proteção do patrimônio histórico e cultural como elemento de identidade e de memória. E é nesse contexto se inclui a proteção dos bens inventariados. O mestre José Afonso da Silva preconiza que os meios de atuação cautelar do patrimônio cultural - constituídos por formas, procedimentos ou instrumentos preordenados para promover e proteger tal bem jurídico - previstos no art. $216, \S 1^{\circ}$, da Constituição Federal de 1988. Em seguida, reconhece-se que:

[...] alguns desses meios são apropriados à formação oficial do patrimônio cultural, por constituírem técnicas jurídicas destinadas a elevar determinado bem à condição de participante desse patrimônio tais são, por exemplo, o inventário, os registros, o tombamento e a desapropriação (DA SILVA, 2001, p. 149 e 155).

O mesmo autor destaca que a tutela dos bens identificados como de valor cultural tem por objetivo defendê-los de ataques, tais como a degradação, o abandono, a destruição total ou parcial, o uso indiscriminado e a utilização para fins desviados, que envilecem o patrimônio, desnaturando seus objetivos.

Segundo leciona Carlos Frederico Marés, citado por Rui Arno Richter:

Independentemente da existência de lei regulamentadora, porém, o Poder Público pode e deve promover o inventário de bens móveis e imóveis para se ter fonte de conhecimento das referências de identidade cultural de que fala a Constituição (MARÉS, apud RICHTER, 2003, p. 60). 
Assim, o inventário tem como um de seus efeitos exatamente a submissão do bem inventariado ao regime jurídico específico dos bens culturais protegidos e a sua qualificação como objeto material dos crimes previstos nos artigos 62 e 63 da Lei 9.605/98, que tutelam os bens protegidos por qualquer tipo de ato administrativo.

Não somente a dogmática jurídico-constitucional, como também as interpretações do Poder Judiciário evoluíram no decorrer das décadas, privilegiando o inventário como instrumento de acautelamento de bens de natureza cultural. Sobre a necessidade de preservação de bens culturais protegidos pelo instrumento do inventário, tem-se consolidado na jurisprudência as seguintes exegeses, perfeitamente aplicáveis ao caso concreto, demonstrando a dissociação entre patrimônio cultural e a figura administrativa do tombamento:

EMENTA: CONSTITUCIONAL. ADMINISTRATIVO. AÇÃO CIVIL PÚBLICA. PATRIMÔNIO CULTURAL. BENS NÃO TOMBADOS. PROTEÇÃO. VIA ADEQUADA. CALÇAMENTO ARTESANAL E HISTÓRICO. INVENTÁRIO. - A ação civil pública é via adequada de proteção de patrimônio cultural representado por bens ainda não tombados. - Deve-se julgar procedente a ação civil pública que visa garantir a proteção e a manutenção de calçamento artesanal e histórico considerado patrimônio cultural municipal e estadual, por meio de inventário, cuja importância foi reconhecida pelo Conselho Municipal e pelo IEPHA/MG. (APELAÇÃO CÍVEL No 1.0460.02.008976-5/001 COMARCA DE OURO FINO - APELANTE(S): MINISTÉRIO PÚBLICO ESTADO MINAS GERAIS - APELADO(A)(S): MUNICÍPIO OURO FINO - RELATOR: EXMO. SR. DES. ALBERTO VILAS BOAS. PUBLICADO AOS 13/03/2009).

No mesmo sentido:

EMENTA: DIREITO ADMINISTRATIVO - AÇÃO CIVIL PÚBLICA LIMINAR - DEFESA DO PATRIMÔNIO HISTÓRICO, ARTÍSTICO E CULTURAL - SUSPENSÃO DE OBRAS EM IMÓVEL NÃO TOMABADO - POSSIBILIDADE. 


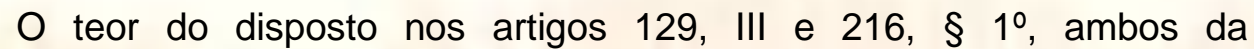
Constituição Federal, a ação civil pública é instrumento hábil para a tutela do patrimônio histórico, artístico e cultural, podendo tal proteção recair em imóvel ainda não tombado. Uma vez presente os requisitos do fumus boni iuris e do periculum in mora, deve ser mantida a liminar que determinou a suspensão de obras realizadas em imóvel cuja preservação de suas características originais é de interesse da comunidade. (AGRAVO DE INSTRUMENTO No 1.0481.08.0868740/001 - COMARCA DE PATROCÍNIO - AGRAVANTE(S): MARCOLINA GONÇALVES E OUTRO(A)(S) - AGRAVADO(A)(S): MINISTÉRIO PÚBLICO ESTADO MINAS GERAIS - RELATOR: EXMO. SR. DES. DÍDIMO INOCÊNCIO DE PAULA. PUBLICADO AOS 24/03/2009).

Ao ser submetido ao procedimento de inventário, o edifício em questão foi guindado ao status de bem cultural, exigindo especial regime jurídicoadministrativo de proteção, não podendo mais ser relegado ao abandono, aos ataques de depredação, à mutilação, à descaracterização e à perda da função social, econômica, ambiental e urbanística. Em consonância com as diretrizes constitucionais, o bem inventariado, porque integrante do patrimônio cultural, se sujeita a medidas restritivas do livre uso, gozo, disposição e reivindicação, tornando-se, por outro lado, obrigatória a sua preservação e conservação para as presentes e futuras gerações. Sobreditas restrições jurídico-administrativas estão em harmonia com a trilogia estrutural do Código Civil de 2002 (assentadas sobre os pilares da eticidade, da sociabilidade e da operabilidade):

Art. 1.228. O proprietário tem a faculdade de usar, gozar e dispor da coisa, e o direito de reavê-la do poder de quem quer que injustamente a possua ou detenha.

$\S 1^{\circ} \mathrm{O}$ direito de propriedade deve ser exercido em consonância com as suas finalidades econômicas e sociais e de modo que sejam preservados, de conformidade com o estabelecido em lei especial, a flora, a fauna, as belezas naturais, o equilíbrio ecológico e o patrimônio histórico e artístico, bem como evitada a poluição do ar e das águas. 
Um dos mandamentos nucleares da ordem constitucional econômica é convolado no princípio da função social da propriedade, como instrumento democrático para se assegurar a todos a existência digna, conforme os ditames da justiça social (artigo 170, inciso III, da Constituição Federal de 1988). Interpretando-se esse preceito normativo de modo sistêmico com o disposto no artigo 216, caput, da Lei Fundamental, vê-se que é dever tanto do Estado (lato sensu), quanto da comunidade, a preservação do patrimônio cultural, dever este de natureza prestacional e positiva, verdadeiro facere.

A proteção do acervo patrimonial especial não redunda em meros deveres negativos ou de abstenção, pois se exigem, hoje, prestações positivas destinadas à manutenção, à defesa e à conservação de bens de natureza cultural, histórica, artística, turística, estética e paisagística. Por evidência que o princípio da função social21 alcança os proprietários particulares de bens declarados de relevância cultural, de maneira que não podem exercer os atributos imanentes ao direito real de propriedade de forma ilimitada e absoluta, tendo por finalidade o atendimento de interesses egoísticos ou meramente econômicos, excedendo os limites ético-sociais e econômicos impostos pelo regime jurídico especial de proteção de tais bens.

Parte-se do pressuposto de que os proprietários de bens culturais não podem exercer o direito incidente sobre eles unicamente em seu próprio e exclusivo interesse, senão em benefício da coletividade, observando-se todo 0 regramento constitucional e legal sobre a proteção do patrimônio cultural, sendo precisamente o cumprimento da função social que legitima o exercício do direito de propriedade. Com base nessa verdadeira função sociocultural, porque materializada pelo efeito declaratório do instrumento de inventário, a Arquidiocese de Uberaba - Paróquia Nossa Senhora do Carmo, proprietária do imóvel em estudo, não pode demolir, modificar, mutilar ou descaracterizar a estrutura física do imóvel sem a anuência do Conselho Municipal do Patrimônio

\footnotetext{
${ }^{21}$ MIRANDA, Marcos Paulo de Souza. Princípios Básicos da Proteção ao Patrimônio Cultural. Artigo disponível em Mestres e Conselheiros. Manual de Atuação dos Agentes do Patrimônio Cultural. Belo Horizonte: IEDS, 2009, p. 17.
} 


\section{ISSN 2447-7656 - Volume IV - Ano III - 2017 Edição Especial, Dezembro}

Cultural, sob pena de incorrer em atos ilícitos que ensejarão a responsabilidade civil, administrativa e penal dos infratores. Igualmente, não é cabível, em sede de ação civil pública, desanuviar questões atinentes à alienação, o tombamento ou a desapropriação do bem imóvel, porquanto se busca a tutela eficaz e adequada à proteção do patrimônio cultural.

Por outro lado, o reconhecimento de que determinado bem tem valor cultural não é privativo do Poder Legislativo ou do Executivo, podendo também ser emanado do Poder Judiciário. Essa a linha preconizada pela Lei $\mathrm{n} . \underline{0}$ 7.347/85, que tornou possível a inclusão de bens no patrimônio cultural brasileiro por meio de decisão judicial, independentemente do critério administrativo.

Não se poderia excluir do debate a hipótese de que a falta de proteção de tais bens decorra exatamente da omissão do Poder Público Municipal, ou seja, da ausência de utilização concreta dos meios de acautelamento previstos na Constituição Federal e nas leis infraconstitucionais (inventário, registro, vigilância, tombamento, desapropriação, etc.). Se os legitimados extraordinários verificaram essas situações, é através da ação civil pública que se buscará a tutela jurisdicional específica. Como já enfatizado, o tombamento não é procedimento constitutivo de valores culturais, pois se limita a declarar a importância cultural de determinado bem, motivo pelo qual se tem admitido que mesmo coisas não tombadas podem ser tuteladas em ação civil pública. Como sintetizado pelo Édis Milaré:

Realmente, a identificação do valor cultural de um bem não emerge da mera criação da autoridade, visto que ele já tinha existência histórica no quadro da sociedade. $O$ fato de um bem determinado pertencer ao patrimônio cultural ou, como diz a lei, ser bem ou direito 'de valor artístico, estético, histórico, turístico e paisagístico', pode ser provado no curso da ação civil pública e referendado por provimento jurisdicional (MILARÉ, 2000, p. 193).

\section{ISSN 2447-7656 - Volume IV - Ano III - 2017 Edição Especial, Dezembro}




\section{ISSN 2447-7656 - Volume IV - Ano III - 2017 Edição Especial, Dezembro}

Oportuno gizar, ainda, que conforme a ficha de inventário do imóvel, o mesmo possui inexorável valor histórico e cultural, motivo pelo qual emerge a necessidade indiscutível de preservação do imóvel. Lado outro, ressalta-se que o Presidente do Conselho Municipal do Patrimônio Cultural de Frutal $^{22}$ deixa clarividente o interesse institucional no tombamento e na preservação do antigo prédio, instância sob a qual funcionaram o Ginásio Frutal, o Colégio São José, o ISPA (Instituto São Paulo Apóstolo), a APAE (Associação de Pais e Amigos dos Excepcionais) e Colégio Objetivo.

Há de ressaltar que mesmo que não houvesse indicação expressa para tombamento, permanece intacto o valor cultural do imóvel, assim como a necessidade de sua preservação. No que diz respeito à responsabilidade do Município de Frutal, mais do que competência legislativa sobre o patrimônio cultural ou a formalização de atos administrativos, como o são o inventário e o tombamento, incumbe a ele a efetiva proteção - por meio de ações concretas de todos os bens culturais existentes em seu território.

Advoga-se que a proteção do patrimônio cultural não está entregue ao alvedrio do gestor público. Cuida-se de atividade administrativa vinculada pelas diretrizes constitucionais e pela legislação local. Todos os instrumentos de efetividade devem ser empregados pelo Poder Público, ante o dever inarredável de proteção, promoção e conservação do patrimônio cultural. Urge trazer à colação o seguinte dispositivo da Lei Ordinária Municipal n. ${ }^{\circ}$ 4.867/2001:

Art. $1^{\circ}$ - Ficam sob a proteção especial do Poder Público Municipal os bens culturais de propriedade pública ou particular existentes no Município de Frutal que, dotados de valor histórico, estético, ético, filosófico ou científico, justifiquem 0 interesse público em sua preservação.

Como ensina Diomar Ackel Filho:

\footnotetext{
22 DUTRA, Ionei. [Entrevista disponibilizada em 10 de maio de 2013, a Internet]. Disponível em: <http://www.frutal.mg.gov.br/Noticias/conselho-de-patrimonio-historico-discute-tombamentos-emfrutal.html >. Acesso em 09/03/2015.
} 
O dever de tutela do Município associado às obrigações federais e estaduais no mesmo sentido não se restringe a uma proteção genérica. Exige-se o cuidado específico quanto à preservação de tais bens em seu conteúdo original. A devastação e o vandalismo que, infelizmente, proliferam em nosso País, sem qualquer respeito a esses valores culturais, justificam a preocupação do legislador constituinte, tornando obrigação também do Município a adoção de medidas eficazes no sentido de garantir a incolumidade desses bens, exercendo com rigor 0 seu poder de polícia no que tange à matéria (ACKEL FILHO, 1992, p. $55)$.

Insofismáveis, ainda, os ensinamentos de Carlos Frederico Marés, quando este nos fala sobre a obrigação do Município em proteger o meio ambiente cultural:

Para cumprir esta obrigação, compete à Administração Municipal organizar serviços próprios, não apenas para que no Plano Diretor sejam respeitados estes bens, mas para que coisas muito mais concretas possam ser aferidas, como, p. ex., não sejam expedidos alvarás ou licenças que ponham em risco o bem pela poluição, perda de visibilidade ou qualquer outra contingência nociva ao uso. $\mathrm{Na}$ organização deste serviço está a primeira competência municipal, oriunda diretamente de sua autonomia: a criação de órgão, serviço ou função que, a partir de critérios dados por normas municipais fiscalizem e protejam os bens culturais (federais, estaduais e municipais) existentes no território do Município. É de se ressaltar que esta é uma competência exclusiva municipal (MARÉS, 1993, p. 33).

Outro não é o posicionamento de Édis Milaré, que enfatiza:

Não mais tem o Poder Público uma mera faculdade na matéria, mas está atado por verdadeiro dever. Transforma-se sua atuação, quanto à possibilidade de ação positiva de defesa e preservação, de discricionária em vinculada. Sai-se da esfera da conveniência e oportunidade para se ingressar num campo estritamente delimitado, o da imposição, onde só cabe um único, e nada mais que único, comportamento: defender e proteger o meio ambiente, a pretexto de que tal não se encontra entre suas prioridades públicas. Repita-se a matéria não mais se insere no campo da discricionariedade administrativa. O Poder Público, a partir da Constituição de 1988, não atua porque quer, mas porque assim the é determinado pelo legisladormaior (MILARÉ, 2000, p. 214 -215). 


\section{ISSN 2447-7656 - Volume IV - Ano III - 2017 Edição Especial, Dezembro}

Por sua vez, aponta, ainda, Álvaro Luiz Valery Mirra:

[...] não há ingerência indevida do Poder Judiciário na esfera de competência do Poder Executivo quando impõe à Administração Pública o cumprimento de obrigações de fazer tendentes à supressão da omissão estatal lesiva ao meio ambiente, pois, na realidade, quem age em iniciativas dessa natureza é a própria sociedade, e o juiz, ao ser provocado, exerce sua atribuição precípua e específica de aplicar o direito aos casos concretos (MIRRA, 2002, p. 381).

Se não bastasse todo o elucidado, no mundo todo há movimentos para o consenso de que não há desenvolvimento onde são suprimidos direitos ou liberdades, dentre estas, se destacam as liberdades políticas e culturais, o que nos leva a concordar ${ }^{23}$ com o pensamento de que "a qualidade de vida nem sempre melhora com o avanço da riqueza material”.

Segundo Veiga:

A expressão desenvolvimento sustentável foi a que acabou se legitimando para negar a incompatibilidade entre o crescimento econômico contínuo e a conservação do meio ambiente. Ou ainda, para afirmar a possibilidade de uma conciliação desses objetivos, isto é, de crescer sem destruir (VEIGA, 2005, p. 19).

A gestão municipal, em anos pretéritos, já tinha sinalizado este movimento ao edificar leis no sentido de criar mecanismos de salvaguarda de bens dotados de importância à memória do seu povo, a saber ${ }^{24}$ :

Lei $\mathbf{n} . \mathbf{4}$ 4.867, de 02 de Outubro de 2001. Estabelece a proteção do patrimônio cultural de Frutal, cria o conselho municipal do patrimônio cultural de Frutal e dá outras providências;

Decreto n. 6.056 A, de 27 de Março de 2003. Cria o conselho municipal do patrimônio cultural do município de Frutal.

Decreto n. 6.600, de 18 de Março de 2005. Decreta o tombamento da imagem de Nossa Senhora do Carmo por seu valor artístico, estilístico, cultural, religioso e histórico;

23 FURTADO, Celso. O Capitalismo Global. São Paulo, Ed. Paz e Terra. 1998 In TORELLY, Luiz Philippe. Patrimônio cultural e desenvolvimento sustentável. Brasília: Iphan, 2012. p. 22.

${ }^{24}$ Disponivel em: http://www.frutal.mg.gov.br/Cultura-Esporte-e-Lazer/home-cultura.html. Acesso em: 20/03/2015. 
Decreto n. $\mathbf{0}$ 7.633, de 06 de abril de 2009. Decreta o tombamento do conjunto paisagístico Parque dos Lagos Leda Campos Borges por seu valor histórico, artístico, arquitetônico, paisagístico e cultural.

Decreto n. 5.517 A, de 30 de Abril de 2009. Institui o Fundo Municipal de Proteção ao Patrimônio Cultural - FUMPAC;

Lei n.o 5.923 A, de 15 de Dezembro de 2011. Cria o Arquivo Público do município de Frutal.

Portanto, apesar da inevitável globalização, há de se ressaltar o caráter indissociável da cultura local e de suas especificidades, a fim de se contrabalancearem as escolhas para que em um futuro próximo não conclamemos por aquilo que se tinha e que, por um descuido, hoje não é passível de ser possuído.

\section{CONCLUSÃO}

Parece-nos arrazoado começarmos pela definição do que vem a ser "cidade" (segundo o modo de entender de Robert Ezra Park, In: VELHO, 1976) para, então, entendermos o papel de suma importância desempenhado pelo ser humano na sua construção:

[...] cidade é algo mais do que um amontoado de homens individuais e de conveniências sociais, ruas, edifícios, luz elétrica, linhas de bonde, telefone, etc.: algo mais também do que uma mera constelação de instituições e dispositivos administrativos - tribunais, hospitais, escolas, polícia e funcionários civis de vários tipos. Antes, a cidade é um estado de espírito, um corpo de costumes e tradições e dos sentimentos e atitudes organizados, inerentes a esses costumes e transmitidos por essa tradição. Em outras palavras, a cidade não é meramente um mecanismo físico e uma construção artificial. Está envolvida nos processos vitais das pessoas que a compõem, é um produto da natureza, e particularmente da natureza humana (VELHO, 1976, p. 24). 
Enquanto que por Estado, conforme os doutrinadores, entendemos como o monopólio legítimo do exercício da força em uma sociedade com caráter monopolista político, passível de ser exercido por diferentes esferas:

\begin{abstract}
Enfim, é o governo que transforma em atos a vontade do Estado, o que é suficiente para fazer dele o poder preponderante sobre todos os demais e exigir dos legisladores um contínuo aperfeiçoamento das normas que regem o funcionamento do Estado e regulam as suas relações com a sociedade, e dos tribunais a constante vigilância da adequação dos atos de governo à legislação, sem que o poder do governo se tornaria tirânico (COELHO, 2012, p. 13-17).
\end{abstract}

Pelos dois textos ora pontuados, pode-se perceber que da noção de cidade e de sociedade é que advém a função do Estado como forma de regular essa interação humana, hoje não tão importante quanto à relação Estado, governo e mercado. E foi este, justamente, o ponto central de discussão do nosso trabalho. Nas últimas décadas, houve uma expansão do conceito de patrimônio cultural, o que levou a extraí-lo da noção de políticas de excepcionalidade, além de incorporá-lo na preservação e na salvaguarda no âmbito das políticas de desenvolvimento sustentável:

Além disso, elas passaram a considerar a dimensão territorial desse patrimônio. Por essa razão, sua integração às demais políticas públicas, em busca de uma relação sincrônica e diacrônica com o desenvolvimento e o futuro, deve apontar para além do que tem sido nossa atuação histórica (TORELLY, 2012, p. 03).

No presente caso, a Gestão Pública Municipal de Frutal/MG age de forma desconexa com o rumo que tem tomado a gestão pública, em nível mundial, ao deixar de considerar aqueles bens passíveis de serem preservados e aqueles que já estão salvaguardados por atos do próprio executivo, como ocorre com o ISPA - Instituto São Paulo Apóstolo, que mesmo estando inventariado e passível de tombamento conforme procedimento administrativo, corre risco de ser destruído para a construção de um edifício residencial. 
À primeira vista, o artigo pode nos remeter a algo sem importância, sem aplicação imediata. Ledo engano! A problemática aqui retratada nos revela o quanto o gestor público deve estar atento às tendências do mundo globalizado. Muito mais que progresso, hoje se fala em progresso sustentável, pois os recursos naturais são escassos, assim como o são os bens passíveis de preservação da história do seu povo.

A gestão pública da cidade de Frutal/MG, em atos concatenados na sucessão do tempo, veio por destruir muitos bens patrimoniais que foram levantados à custa da história de seus habitantes, enquanto que, em algumas cidades mineiras, os gestores souberam tirar proveito desta peculiar característica e geraram, e continuam gerando, empregos e impostos com a exploração do turismo regional.

É por estas e outras questões, que o presente trabalho focou na importância que pode desempenhar um determinado bem, que, dotado de personalidade patrimonial, devido aos seus valores intrínsecos e extrínsecos, pode fazer passar de geração a geração a luta desempenhada à época por um povo ou grupo de indivíduos, o que, por si só, já é condição para sobrepor os anseios particulares e exigir a efetivação dos instrumentos adequados ao reconhecimento e sua guarda.

Assim sendo, o presente artigo buscou exemplificar, por meio do estudo de um caso prático, a importância de, enquanto gestores públicos, refletirmos acerca da necessária preservação e incorporação do patrimônio cultural como promoção da qualidade de vida e do bem-estar social a ser observado no âmbito das políticas públicas de desenvolvimento sustentável.

Cabe ressaltar que hoje os tempos são outros. Dificilmente um gestor público, arbitrariamente, conseguiria destruir um bem dotado de historicidade sem ser criticado quase que instantaneamente pelas mídias sociais.

\section{ISSN 2447-7656 - Volume IV - Ano III - 2017 Edição Especial, Dezembro}


Some-se a isso a atuação do Ministério Público que, como curador do patrimônio histórico e cultural, é instituição responsável pela defesa dos direitos sociais e individuais indisponíveis. Essa instituição, por ser independente, não sofre influência das vontades da gestão pública, muito pelo contrário, sua emancipação lhe garante um trabalho imparcial, cabendo somente que alguém o provoque.

Em suma, cada vez mais as políticas de desenvolvimento sustentável e a dimensão de cultura estarão inseridas às outras dimensões do desenvolvimento, levando o gestor público a buscar alternativas condizentes com esta nova realidade.

\section{REFERÊNCIAS}

ACKEL FILHO, Diomar. Município e prática municipal à luz da Constituição Federal de 1988. São Paulo: Revista dos Tribunais. 1992.

BRASIL. Constituição da República Federativa do Brasil: promulgada em 5 de outubro de 1988. 44 ed. São Paulo: Saraiva, 2010.

BERNARDES, Samir Alouan. [Leis]. Disponível em: http://www.frutal.mg.gov.br/Cultura-Esporte-e-Lazer/home-cultura.html

CARSALADE, Flávio de Lemos. A Ética das Intervenções. Artigo disponível em Mestres e Conselheiros. Manual de Atuação dos Agentes do Patrimônio Cultural. Belo Horizonte: IEDS, 2009.

CASTRIOTA, Leonardo Barci. Patrimônio Cultural, Valores e Sociedade Civil. Artigo disponível em Mestres e Conselheiros. Manual de Atuação dos Agentes do Patrimônio Cultural. Belo Horizonte: IEDS, 2009.

. Patrimônio Cultural: conceitos, políticas, instrumentos. São Paulo: Annablume. Belo Horizonte: IEDS, 2009.

CASTRO, Sônia Rabelo de. O Estado na Preservação dos Bens Culturais. Rio de Janeiro: Renovar, 1991.

COELHO, Ricado Corrêa. Estado, governo e mercado. Florianópolis: Departamento de Ciências da Administração / UFSC, 2012, p. 13/17.

DA SILVA, José Afonso. Ordenação Constitucional da Cultural. São Paulo: Malheiros. 2001. 
DUTRA, Ionei. [Entrevista - disponibilizada em 10 de maio de 2013, a Internet]. Disponível em: <http://www.frutal.mg.gov.br/Noticias/conselho-de-patrimoniohistorico-discute-tombamentos-em-frutal.html>.

FERREIRA, Jeová. Original História de Frutal. Frutal: Oficina de Artes Yara Lins, 2002.

FERREIRA, Terezinha Lamounier. Respingos de História III. Registro de Fatos Pessoais e Acontecimentos Históricos de Frutal. Frutal: Oficina das Artes Yara Lins, 2009.

GINÁSIO (ESCOLA). In: WIKIPÉDIA: a enciclopédia livre. Flórida: Wikimedia Foundation, 2013. Disponível em: <http://pt.wikipedia.org/wiki/Gin\%C3\%A1sio_(escola)>.

MARCHESAN, Ana Maria Moreira. A tutela do Patrimônio Cultural sob o enfoque do Direito Ambiental. $1^{\text {a }}$ Ed. Ed livraria do Advogado. Porto Alegre. 2007.

MARÉS, Carlos Frederico. A proteção jurídica dos bens culturais. Cadernos de Direito Constitucional e Ciência Política. São Paulo, nº 2. 1993.

MILARÉ, Edis. Direito do ambiente. São Paulo: Revista dos Tribunais. 2000.

MIRANDA, Marcos Paulo de Souza. Princípios Básicos da Proteção ao Patrimônio Cultural. Artigo disponível em Mestres e Conselheiros. Manual de Atuação dos Agentes do Patrimônio Cultural. Belo Horizonte: IEDS, 2009.

MIRRA, Álvaro Luiz Valery. Ação civil pública e a reparação do dano ao meio ambiente. São Paulo: Juarez de Oliveira, 2002.

PAULA, Álvaro Ferreira de. Desbravador do Carmo de Fructal - História e Genealogia de um Descendente. [s.I]: Edição Independente de 2004.

PARK, Robert Ezra. A cidade: sugestões para a investigação do comportamento humano no meio urbano. In: VELHO, Otávio Guilherme (org.). O fenômeno urbano. 3. ed. Rio de Janeiro: Zahar 1976, p. 24.

RICHTER, Rui Arno. Meio Ambiente Cultural: Omissão e Tutela Judicial. $1^{\text {a }}$ Ed. Ed. Juruá. Curitiba. 2003.

SECOM. Disponível em http://www.frutal.mg.gov.br/Cultura-Esporte-eLazer/bens-inventariados-imoveis.html. Acesso: 20/03/2015.

TORELLY, Luiz Philippe. Patrimônio cultural e desenvolvimento sustentável. Anais; v. 3 - Brasilia, DF: Iphan, 2012, p. 03.

\section{ISSN 2447-7656 - Volume IV - Ano III - 2017 Edição Especial, Dezembro}

